\title{
Ductile Bulk Metallic Glass
}

\author{
Jan Schroers ${ }^{1,2, *}$ and William L. Johnson ${ }^{1}$ \\ ${ }^{1}$ Keck Laboratory of Engineering Materials, California Institute of Technology, Pasadena, California 91125, USA \\ ${ }^{2}$ Liquidmetal Technologies, Lake Forest, California 92630, USA
}

(Received 2 August 2004; published 16 December 2004)

\begin{abstract}
We report on experimental evidence of pronounced global plasticity measured in monolithic $\mathrm{Pt}_{57.5} \mathrm{Cu}_{14.7} \mathrm{Ni}_{5.3} \mathrm{P}_{22.5}$ bulk metallic glass under both bending and unconfined compression loading conditions. A plastic strain of $20 \%$ is measured, never before seen in metallic glasses. Also, permanent deformation and a strain exceeding $3 \%$ before failure is observed during bending of $4 \mathrm{~mm}$ thick samples. To date, no monolithic metallic material has exhibited such a combination of high strength, extensive ductility, and high elastic limit. The large plasticity is reflected in a high Poisson ratio of 0.42 , which causes the tip of a shear band to extend rather than initiate a crack. This results in the formation of multiple shear bands and is the origin of the observed large global ductility and very high fracture toughness, approximately $80 \mathrm{MPam}^{-1 / 2}$.
\end{abstract}

DOI: 10.1103/PhysRevLett.93.255506

The absence of crystal-slip mechanisms in bulk metallic glasses (BMGs) leads to very high yield strength values close to the theoretical limit [1]. BMGs do not show strain hardening during deformation as crystalline (ductile) metals do, but instead exhibit strain softening and thermal softening due to adiabatic heating [2-4]. Upon yielding, BMGs tend to form shear bands in which plastic deformation occurs in a highly localized manner [5]. In an unconfined geometry, failure of the BMG occurs typically along a single shear band that cuts across the sample at an angle of $45^{\circ}$ (direction of maximum resolved shear stress) with respect to the compression axis [6]. This limits the global plasticity of BMGs in unconfined geometries to less than $1 \%$ and restricts the use of BMGs as a structural material for most applications.

In an effort to overcome the problem of limited plasticity of BMG at room temperature and to develop structural materials, efforts have focused on the fabrication of BMG composites. A variety of composite materials have been made by introducing a second crystalline phase into the liquid BMG [7] or by in situ formation of a crystalline phase during partial crystallization [8-10]. The underlying goal in enhancing plasticity in BMG composites is to prevent a single shear band from traversing through the sample and to generate multiple shear bands.

In this Letter we report for the first time on a monolithic BMG that shows a large global plasticity. The plasticity was observed during bending and unconfined compression and is a consequence of the large Poisson ratio of the material.

Amorphous $\mathrm{Pt}_{57.5} \mathrm{Cu}_{14.7} \mathrm{Ni}_{5.3} \mathrm{P}_{22.5}$ was prepared by inductively melting the constituents in $12 \mathrm{~mm}$ quartz tubes under an argon atmosphere [11]. The alloyed $\mathrm{Pt}_{57.5} \mathrm{Cu}_{14.7} \mathrm{Ni}_{5.3} \mathrm{P}_{22.5}$ was subsequently fluxed with $\mathrm{B}_{2} \mathrm{O}_{3}$ for $1200 \mathrm{~s}$ at $1000 \mathrm{~K}$, a process which is known to improve the glass forming ability $[12,13]$. Water quenching resulted in an amorphous sample. The amorphous nature of the $\mathrm{Pt}_{57.5} \mathrm{Cu}_{14.7} \mathrm{Ni}_{5.3} \mathrm{P}_{22.5}$ samples studied in this investigation
PACS numbers: 81.05.Kf, 62.20.Fe, 81.05.Zx, 83.60.Rs

was confirmed by x-ray diffraction, thermal analysis, and microscopy.

Bar shaped samples with dimensions of $3 \mathrm{~mm} \times$ $3 \mathrm{~mm} \times 6 \mathrm{~mm}$ were machined for quasistatic $(\dot{\varepsilon}=$ $10^{-4} \mathrm{~s}^{-1}$ ) compression tests. Figure 1 shows the stressstrain curve of a $\mathrm{Pt}_{57.5} \mathrm{Cu}_{14.7} \mathrm{Ni}_{5.3} \mathrm{P}_{22.5}$ sample under compressive loading. Initially, it behaves like a typical BMG, exhibiting an elastic strain limit of less than $2 \%$ at a yield stress of $1400 \mathrm{MPa}$. However, after reaching the maximum strength of $1470 \mathrm{MPa}$, the material deforms in a perfectly plastic manner. This has never been observed for BMGs, which typically fail before any observable plastic deformation occurs. The plastic strain to failure was found to be $20 \%$.

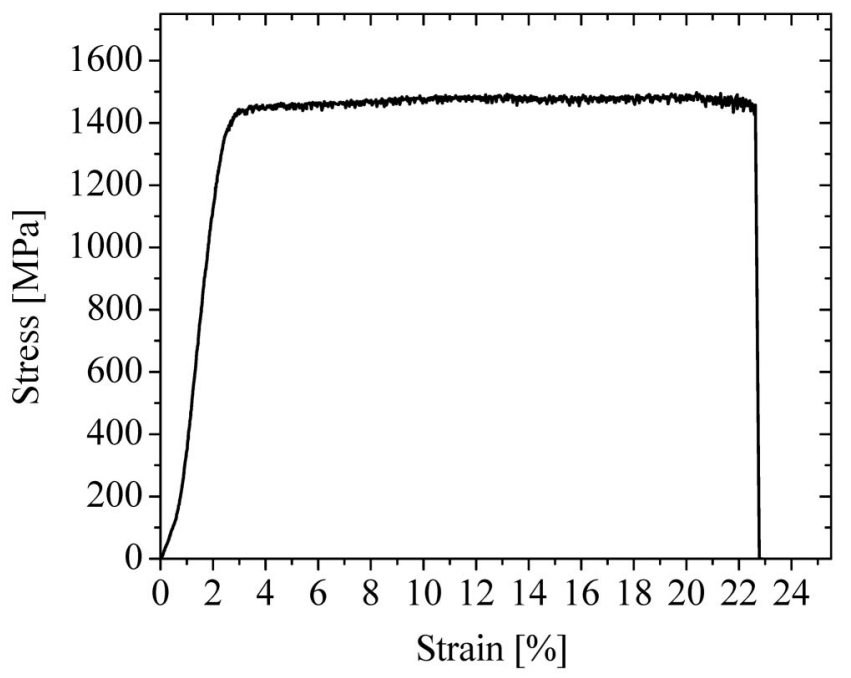

FIG. 1. Stress-strain curve of amorphous monolithic $\mathrm{Pt}_{57.5} \mathrm{Cu}_{14.7} \mathrm{Ni}_{5.3} \mathrm{P}_{22.5}$. The curve was determined under quasistatic compression of a bar shaped sample with $3 \mathrm{~mm} \times$ $3 \mathrm{~mm} \times 6 \mathrm{~mm}$ dimensions. The material undergoes about $20 \%$ plastic deformation before failure. 


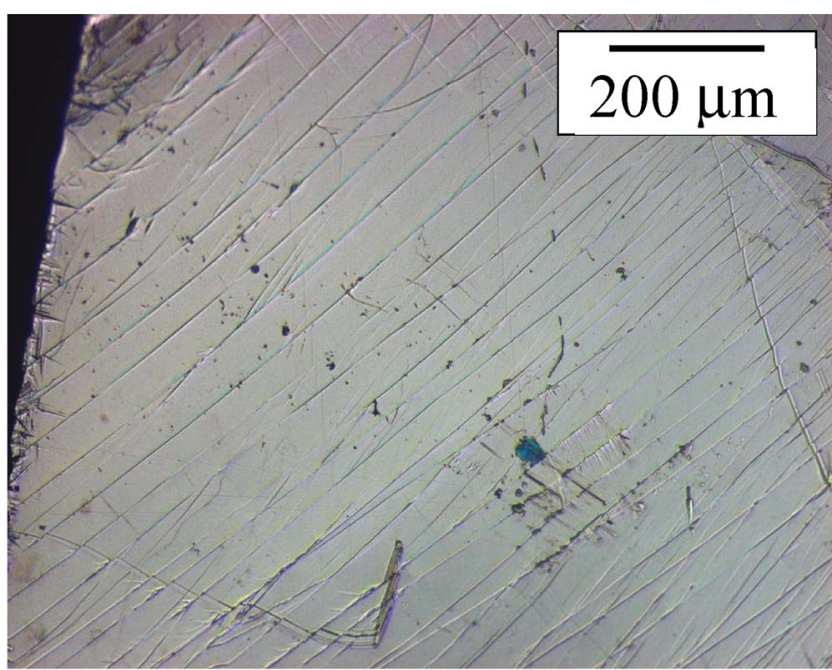

FIG. 2 (color online). Optical micrographs of $\mathrm{Pt}_{57.5} \mathrm{Cu}_{14.7} \mathrm{Ni}_{5.3} \mathrm{P}_{22.5}$ metallic glass that was plastically deformed to $15 \%$ strain. The primary shear band spacing is about $30 \mu \mathrm{m}$ and that of the secondary bands is about $7 \mu \mathrm{m}$.

Samples were polished prior to plastic deformation. Figure 2 shows an optical micrograph of a sample that was loaded in compression to $15 \%$ strain. Typically, in an unconfined geometry the formation one shear band leads to failure of the BMG. In this sample, however, a large number of shear bands can be observed. In addition to the primary shear bands that form an angle of approximately $45^{\circ}$ with respect to the compression axis, some secondary shear bands form with an angle of approximately $45^{\circ}$ with respect to the primary bands. The average spacing of the primary bands is about $30 \mu \mathrm{m}$, and the average shear offset is about $1 \mu \mathrm{m}$.

In order to investigate if the high ductility also leads to a high crack resistance, fracture toughness measurements were performed. Fracture toughness testing was conducted on $24 \mathrm{~mm} \times 6 \mathrm{~mm} \times 4 \mathrm{~mm}$ samples. The samples were prenotched to a length of $3 \mathrm{~mm}$ with a notch radius of $50 \mu \mathrm{m}$. A standard three point beam geometry with a load rate of $10^{-6} \mathrm{~m} / \mathrm{s}$ was used. Fracture toughness was calculated according to ASTM E399-90 standard. Two samples were tested and values of $K_{1 c}=79 \mathrm{MPa} \mathrm{m}^{-1 / 2}$ and $K_{1 c}=$ $84 \mathrm{MPa} \mathrm{m}^{-1 / 2}$ were calculated. This very high $K_{1 c}$ value is also reflected in the large plastic zone extending from the notch into the sample. Figure 3 shows an image of the plastic zone measured on a sample with a notch radius of $200 \mu \mathrm{m}$. The size of the notch tip plastic zone (as defined by the extent of visible shear bands) is about $1.4 \mathrm{~mm}$, nearly an order of magnitude larger than measured on $\mathrm{Zr}$ based BMGs [14]. In Zr-based BMGs, measured fracture toughness values are between $K_{1 c}=16 \mathrm{MPa} \mathrm{m}^{-1 / 2}$ [15] and $K_{1 c}=20 \mathrm{MPa} \mathrm{m}^{-1 / 2}$ [16].

The critical crack radius can be calculated according to $a=2 K_{1 c}^{2} / \sigma_{y}^{2} \sqrt{\pi}$. With the measured $K_{1 c}=$ $80 \mathrm{MPa} \mathrm{m}^{-1 / 2}$ and $\sigma_{y}=1400 \mathrm{MPa}$, a critical crack radius

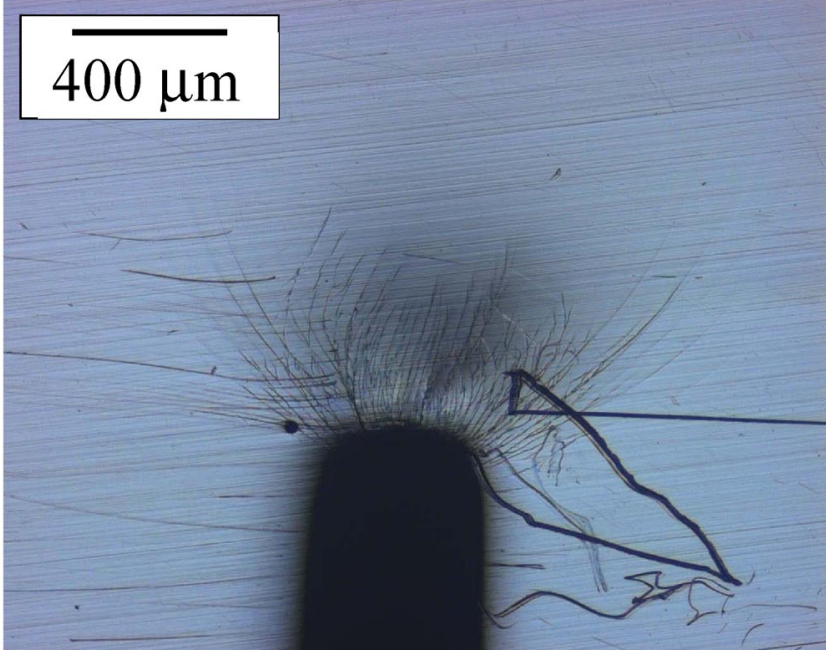

FIG. 3 (color online). Plastic zone ahead of the notch in a three point beam bending test. The shear bands extend to about $1.4 \mathrm{~mm}$ into the sample. Note that the $200 \mu \mathrm{m}$ notch radius in this figure is different from the notch radius of $50 \mu \mathrm{m}$ used for fracture toughness samples.

of $4 \mathrm{~mm}$ is calculated. This radius is about 40 times larger than the critical crack radius in a Zr-based BMG $(100 \mu \mathrm{m})$ [6]. The large critical crack radius for $\mathrm{Pt}_{57.5} \mathrm{Cu}_{14.7} \mathrm{Ni}_{5.3} \mathrm{P}_{22.5}$ suggests that the material's mechanical properties are very insensitive to porosity and inclusions.

Bending tests were performed on $4 \mathrm{~mm} \times 4 \mathrm{~mm} \times$ $35 \mathrm{~mm}, \quad 2 \mathrm{~mm} \times 4 \mathrm{~mm} \times 15 \mathrm{~mm}$, and $1.8 \mathrm{~mm} \times$ $3 \mathrm{~mm} \times 15 \mathrm{~mm}$ bar shaped samples that were bent around mandrels of radius of $60,12.7,9.5$, and $6.35 \mathrm{~mm}$. The $1.8 \mathrm{~mm}$ thick sample did not fail during bending over all four mandrels, as can be seen in Fig. 4(a). The strain to failure can be calculated from $\varepsilon=h / 2 R$, where $R$ is the neutral radius of the bend sample and $h$ is the sample's thickness. For the $4 \mathrm{~mm}$ thick sample the strain to failure exceeds $3 \%$ as evidenced by the permanent deformation of the sample shown in Fig. 4(b). A strain to failure between $10.5 \%$ and $15.7 \%$ was observed for the $2 \mathrm{~mm}$ thick sample, and the $1.8 \mathrm{~mm}$ sample exceeded $14.2 \%$ strain.

Figure 5 shows micrographs of a $1.8 \mathrm{~mm} \times 3 \mathrm{~mm} \times$ $15 \mathrm{~mm}$ sample that was bent over mandrels of radii

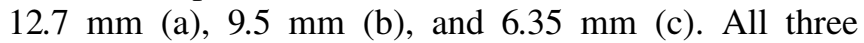
microstructures show multiple shear band formation with similar shear band spacings of approximately $50 \mu \mathrm{m}$. The plastic zone depth on both the compression and the tension side of each sample is similar and increases from $700 \mu \mathrm{m}$ (a) to $800 \mu \mathrm{m}$ (b) to $840 \mu \mathrm{m}$ in (c). The shear offsets in all three microstructures are around $5 \mu \mathrm{m}$.

Plastic deformation in metallic glasses during bending was observed only in thin samples [17-19], and a direct correlation between sample thickness and plastic strain to failure was observed [20]. The increase of plasticity with decreasing sample thickness was explained by Conner et al. [20] as a geometric effect. The authors argue that 

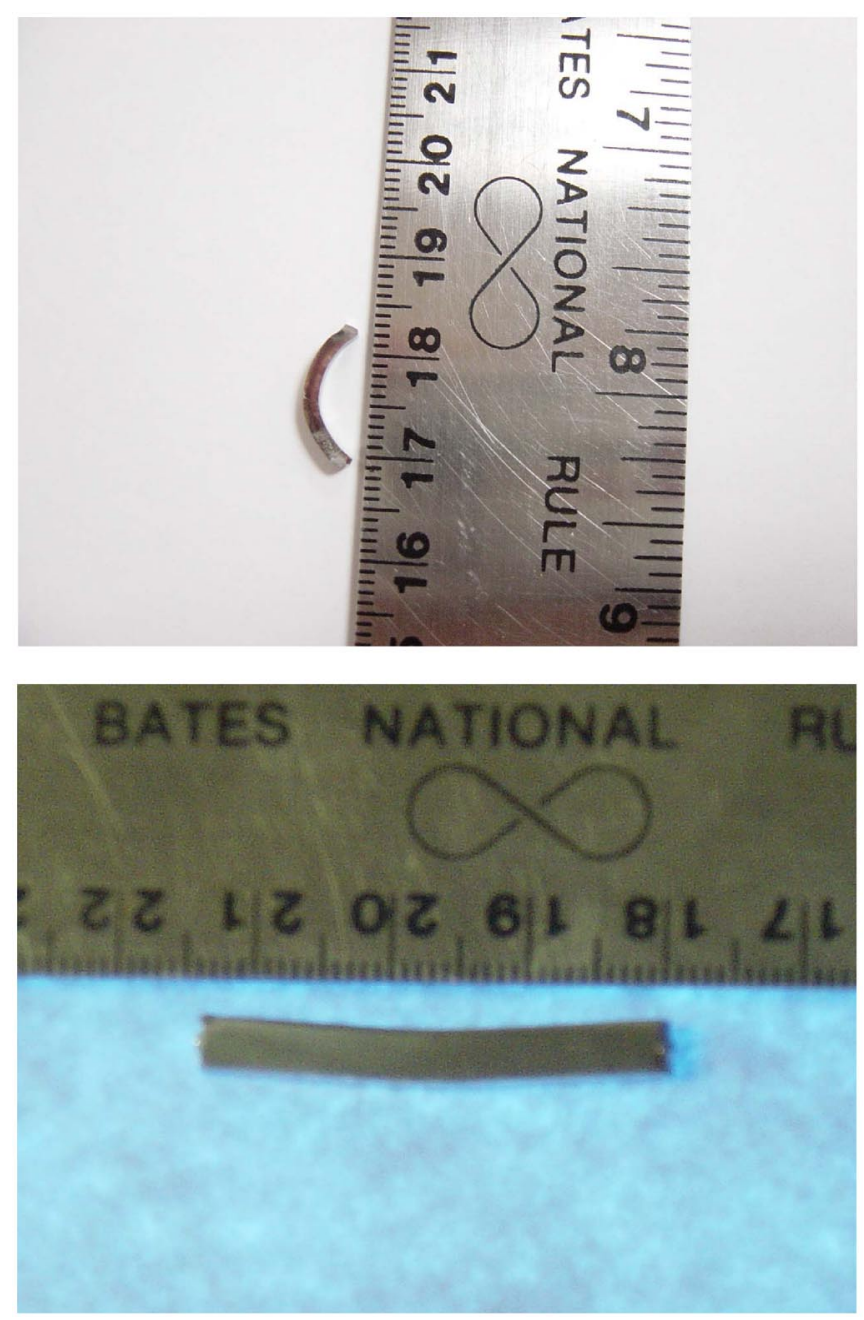

FIG. 4 (color online). (a) A $1.8 \mathrm{~mm} \times 3 \mathrm{~mm} \times 15 \mathrm{~mm}$ bar shaped $\mathrm{Pt}_{57.5} \mathrm{Cu}_{14.7} \mathrm{Ni}_{5.3} \mathrm{P}_{22.5}$ sample bent over a mandrel of radius $6.35 \mathrm{~mm}$. The strain to failure exceeds $14.2 \%$. (b) $\mathrm{Pt}_{57.5} \mathrm{Cu}_{14.7} \mathrm{Ni}_{5.3} \mathrm{P}_{22.5}$ samples with dimensions of $4 \mathrm{~mm} \times$ $4 \mathrm{~mm} \times 34 \mathrm{~mm}$ bent over a mandrel with a radius of $6 \mathrm{~cm}$. The strain to failure exceeds $3 \%$.

the shear displacement in a band scales with the band's length, which in turn scales with a sample's thickness. Since crack initiation scales with the shear displacement, thicker samples fail at much smaller plastic strains than thinner samples do. Plastic strains to failure similar to those measured in the present study on $4 \mathrm{~mm}$ thick samples were observed in $\mathrm{Zr}$-based BMGs that are an order of magnitude thinner. For Zr-based BMGs thicker than $1 \mathrm{~mm}$ no plasticity at all was observed [20].

Ultrasonic measurements were carried out to determine the sound velocity in amorphous $\mathrm{Pt}_{57.5} \mathrm{Cu}_{14.7} \mathrm{Ni}_{5.3} \mathrm{P}_{22.5}$. Elastic constants were calculated from the sound velocities and are shown in Table I. The elastic strain limit of $1.48 \%$ is calculated from the yield stress, $\sigma_{y}=1400 \mathrm{MPa}$, determined from the compression test, and Young's modulus, $E=94.8 \mathrm{GPa}$, determined from the speed of sound measurements. The $\mathrm{Pt}_{57.5} \mathrm{Cu}_{14.7} \mathrm{Ni}_{5.3} \mathrm{P}_{22.5} \mathrm{BMG}$ exhibits an un-
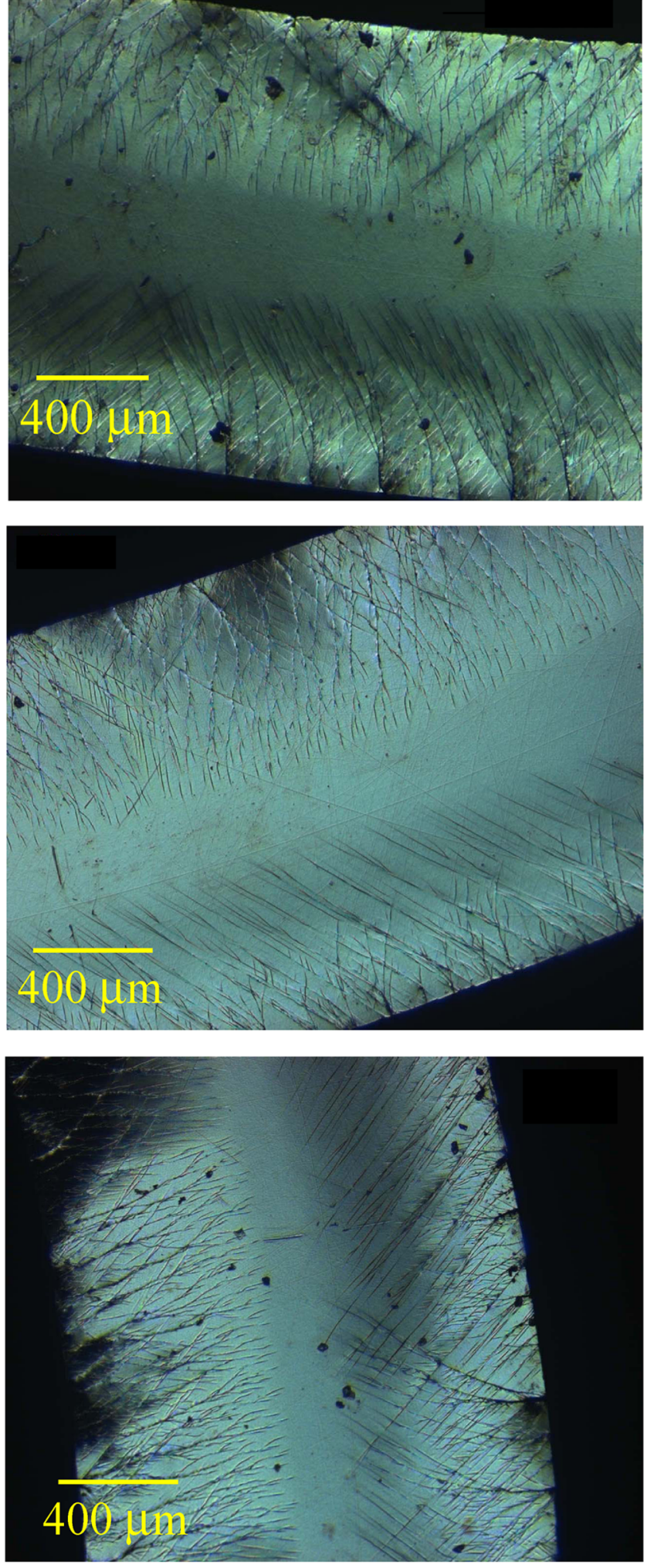

FIG. 5 (color online). Optical micrograph of a $\mathrm{Pt}_{57.5} \mathrm{Cu}_{14.7} \mathrm{Ni}_{5.3} \mathrm{P}_{22.5} \quad$ BMG with dimensions of $1.8 \mathrm{~mm} \times$ $3 \mathrm{~mm} \times 15 \mathrm{~mm}$ which was bent (a) over a mandrel of radius $12.7 \mathrm{~mm}$, which corresponds to a strain of about $7 \%$, (b) over a mandrel with radius $9.5 \mathrm{~mm}$, which corresponds to a strain of about $9 \%$, and (c) over a mandrel of radius $6.35 \mathrm{~mm}$, which corresponds to a strain of about $14 \%$. 
TABLE I. Elastic constants for amorphous $\mathrm{Pt}_{57.5} \mathrm{Cu}_{14.7} \mathrm{Ni}_{5.3} \mathrm{P}_{22.5}$, calculated from ultrasonic measurements of the transverse speed of sound, $v_{t}$, and the longitudinal speed of sound, $v_{l}$. $G$ denotes the shear modulus, $B$ the bulk modulus, $E$ Young's modulus, $\rho$ the alloy's density, and $\nu$ Poisson's ratio.

$\overline{v_{t}(\mathrm{~m} / \mathrm{s}) v_{l}(\mathrm{~m} / \mathrm{s}) \rho\left(\mathrm{g} / \mathrm{cm}^{3}\right) G(\mathrm{GPa}) B(\mathrm{GPa}) E(\mathrm{GPa}) \quad \nu}$

\begin{tabular}{lllllll}
1481.5 & 4000 & 15.02 & 33.3 & 198.7 & 94.8 & 0.42 \\
\hline
\end{tabular}

usually low ratio of shear modulus, $G$, to bulk modulus, $B$, of 0.165 . This is about a factor of 2 smaller than the $G / B=$ 0.31 measured for $\mathrm{Zr}_{41} \mathrm{Ti}_{14} \mathrm{Cu}_{12} \mathrm{Ni}_{10} \mathrm{Be}_{23}$ (Vit1) [20]. The low $G / B$ is also reflected in the high Poisson ratio of 0.42 , compared to 0.36 for Vit1. A small $G / B$ ratio allows for shear collapse before the extensional instability of crack formation can occur. This causes the tip of a shear band in $\mathrm{Pt}_{57.5} \mathrm{Cu}_{14.7} \mathrm{Ni}_{5.3} \mathrm{P}_{22.5}$ to extend rather than to initiate a crack. Deformation is therefore accomplished by the formation of multiple shear bands, which results in the observed large global ductility and very high fracture toughness. In fact, in crystalline materials a low $G / B$ ratio is a good phenomenological indicator of inherent ductility. For example, Hecker et al. [21] found that the ductile fcc metals all have a low $G / B$, whereas brittle bcc metals have a high $G / B$.

During heating, BMGs undergo a transition in their deformation mode (see, e.g., [22]). At low temperatures they deform in a highly inhomogeneous manner and form localized shear bands with no global plasticity. With increasing temperature, deformation becomes homogeneous and they exhibit a large plasticity in the vicinity of $T g$. This suggests that BMGs with low $T g$ values, closer to room temperature where mechanical properties are typically determined, are more likely to exhibit room temperature ductility. This is supported by the low $T g$ value of $508 \mathrm{~K}$ for $\mathrm{Pt}_{57.5} \mathrm{Cu}_{14.7} \mathrm{Ni}_{5.3} \mathrm{P}_{22.5}$ [11].

In summary, this Letter reports on a large global plasticity in $\mathrm{Pt}_{57.5} \mathrm{Cu}_{14.7} \mathrm{Ni}_{5.3} \mathrm{P}_{22.5} \mathrm{BMG}$ observed in unconfined compression and bending geometry. In sharp contrast to typical bulk metallic glasses which do not show any noticeable plasticity, $\mathrm{Pt}_{57.5} \mathrm{Cu}_{14.7} \mathrm{Ni}_{5.3} \mathrm{P}_{22.5}$ exhibits a plastic strain to failure of $20 \%$ in compression and a strain to failure that exceeds $3 \%$ during bending of a $4 \mathrm{~mm}$ thick sample. To date, no monolithic metallic material does exhibit such a combination of high strength, extensive ductility, and high elastic limit. The large ductility is a consequence of the formation of a high density of shear bands. Obviously, the shear bands cannot transform themselves into cracks easily. The small ratio of shear modulus to bulk modulus causes the tip of a shear band to extend rather than initiate a crack because the low shear modulus allows for shear collapse before the extensional instability of crack formation can occur. This results in the formation of multiple shear bands and is the origin of the observed high global ductility and very high fracture toughness of approximately $80 \mathrm{MPam}^{-1 / 2}$. Overall, a large Poisson ratio and a low glass transition temperature might be regarded as indicators of the ductile character of a bulk metallic glass and could therefore be used as a means of identifying ductile bulk metallic glasses.

We thank Professor William D. Nix, Dr. R. Dale Conner, Professor Ralf Busch, and Dr. Theodore A. Waniuk for very helpful discussions.

*Corresponding author.

Electronic address: schroers@caltech.edu

[1] A. L. Greer, Science 267, 1947 (1995).

[2] P. S. Stief, F. Spaepen, and J. W. Hutchinson, Acta Metall. 30, 447 (1982).

[3] H. Chen, Y. He, G. J. Shiflet, and S. J. Poon, Nature (London) 367, 541 (1994).

[4] K. M. Flores and R. H. Dauskardt, J. Mater. Res. 14, 638 (1999).

[5] F. Spaepen, Acta Metall. 25, 407 (1977).

[6] W. L. Johnson, MRS Bull. 24, 42 (1999).

[7] H. Choi-Yim and W. L. Johnson, Appl. Phys. Lett. 71, 3808 (1997).

[8] C. C. Hays, C. P. Kim, and W. L. Johnson, Phys. Rev. Lett. 84, 2901 (2000).

[9] C. Fan and A. Inoue, Appl. Phys. Lett. 77, 46 (2000).

[10] U. Kuhn, J. Eckert, N. Mattern, and L. Schultz, Appl. Phys. Lett. 80, 2478 (2002).

[11] J. Schroers and W. L. Johnson, Appl. Phys. Lett. 84, 3666 (2004).

[12] H. W. Kui, A. L. Greer, and D. Turnbull, Appl. Phys. Lett. 45, 615 (1984).

[13] J. Schroers, Y. Wu, and W. L. Johnson, Philos. Mag. A 82, 1207 (2002).

[14] K. M. Flores and R.H. Dauskardt, Scr. Mater. 41, 937 (1999).

[15] C. J. Gilbert, R. O. Ritchie, and W. L. Johnson, Appl. Phys. Lett. 71, 476 (1997).

[16] P. Lowhaphandu and J. J. Lewandowski, Scr. Metall. 38, 1881 (1998).

[17] D. G. Ast and D. J. Krenitsky, Mater. Sci. Eng. 43, 241 (1980).

[18] E. P. Barth, F. Spaepen, R. Bye, and S. K. Das, Acta Mater. 45, 423 (1997).

[19] A. Inoue, X. M. Wang, Acta Mater. 48, 1383 (2000).

[20] R. D. Conner, W. L. Johnson, N. E. Paton, and W. D. Nix, J. Appl. Phys. 94, 90 (2003).

[21] S. S. Hecker, D. L. Rohr, and D. F. Stein, Metall. Trans. 9, 481 (1978).

[22] W. L. Johnson, J. Lu, and M. D. Demetrious, Intermetallics 10, 1039 (2002). 